\title{
Synthesis and Photophysical Behaviours of Novel Phenanthro[9,10-d] imidazole Substituted Azo Dyes in Solvent Media
}

\author{
Seçil Çelik Erbaş ${ }^{1, *}$, Sibel Gülle ${ }^{2}$ \\ ${ }^{1}$ Manisa Celal Bayar University, Faculty of Engineering, Department of Metallurgy and Materials Engineering, \\ Campus of Şehit Prof. Dr. İlhan Varank, 45140, Manisa, Turkey \\ ${ }^{2}$ Manisa Celal Bayar University, Faculty of Arts and Science, Department of Chemistry, Campus of Şehit Prof. Dr. \\ İlhan Varank, 45140, Manisa, Turkey \\ *secil.celik@cbu.edu.tr
}

Received: 14 May 2018

Accepted: 21 September 2018

DOI: $10.18466 /$ cbayarfbe.423419

\begin{abstract}
In this study, three novel phenanthroimidazole derivatives containing azo group were synthesized and their photophysical properties were investigated. For this purpose, 2-(4-nitrophenyl) $1 H$-phenanthro[9,10d] imidazole structure obtained from 9,10-phenanthroquinone and 4-nitrobenzaldehyde was reduced with palladium on activated charcoal $10 \%$ and hydrazine hydrate. Phenanthro[9,10- $d]$ imidazole-2-yl)aniline obtained in this way was converted to phenantroimidazole-azo derivatives containing different aromatic groups. Structural analyses were performed by FT-IR, NMR, LC-MS spectroscopic techniques. Spectral characterizations and photostability studies of phenanthroimidazole derivatives were performed by UV-vis and fluorescence spectroscopy in solvent media. The maximum absorption and emission wavelengths, molar extinction coefficients, singlet energy levels, Stokes' shift values of phenanthroimidazole-azo derivatives were obtained.
\end{abstract}

Keywords: Phenanthroimidazole, azo group, fluorescence spectroscopy, dye-solvent interaction.

\section{Introduction}

Azo dyes are one of the most important commercial colorants with their favorable properties separated from other dye classes such as wide color ranges, high fastness and color intensities [1-2]. They are also used for the coloring paper, nonlinear optic materials and textile [35]. Numerous different molecules can be connected with each other by means of the azo bridge $(-\mathrm{N}=\mathrm{N}-)$. In this way, the color properties (color intensity, wavelength etc.) of the organic dyes can be changed by extending the conjugation. Five membered heterocycles, especially imidazoles, have been used in the synthesis of many dyes as conjugated $\pi$ systems. Phenanthroimidazoles have a larger conjugate system than the imidazole ring. Phenanthroimidazole based compounds have a wide application area and can be used as a dye-sensitizer in solar cells, organic light emitting diodes, solid state fluorescence applications, organic emitters in blue-light emitting materials and optic chemosensors [6-10].

Synthetic studies on phenanthroimidazole derivatives gain significant interest since early 1970s [11-12]. There are several studies in literature about the synthesis of azo dyes containing imidazole and benzimidazole rings [1314]. Phenanthroimidazole ring is a newer unit for azo dyes and phenanthroimidazole-azo structure can be used at various applications addition to the other azo classes.

In this study, three novel phenanthroimidazole substituted azo dyes (PA) were synthesized (Figure 1). The most general synthesis procedure is the condensation reaction of 9,10- phenanthrenequinone with 4-nitrobenzaldehyde in the presence of ammonium acetate and acetic acid [15]. The nitro group of the phenanthroimidazole compound was first reduced to the amino group [16], afterwards azo coupling reaction was carried out with aromatic rings which have different electron donating groups $[17,18]$. Absorption, fluorescence and photostability measurements were performed in the solvent media. 


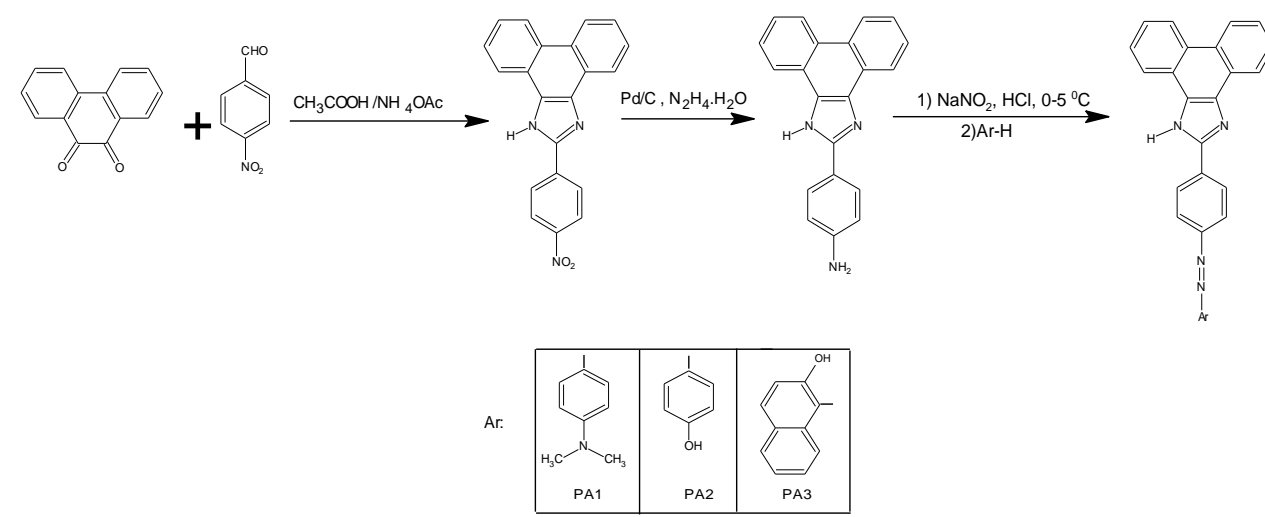

Figure 1. Synthetic pathways of phenanthroimidazole-azo derivatives.

In the literature, there are azo dyes which have imidazole and benzimidazole rings but synthesis of phenanthroimidazole based azo dyes are limited. The new long conjugated phenanthroimidazole azo dyes which have electron donor groups were obtained with this study. It is thought that these dyes can be used for sensor and luminescence applications due to their longer conjugation and photostability behaviours.

\section{Materials and Methods}

All reagents were obtained from Sigma Aldrich and Merck. Solvents used in spectroscopic studies were of analytical grade and used without a purification process.

FT-IR spectra were recorded on a Perkin ElmerSpectrum BX spectrophotometer. NMR spectra were determined with a Varian $400 \mathrm{MHz}$ spectrometer. LCMS analyses were performed with an Agilent Technologies 1260 Infinity liquid chromatography system hyphenated to a 6420 Triple Quad mass spectrometer. UV-vis spectra were measured on a Shimadzu UV-1800 spectrophotometer. Fluorescence measurements were performed using a Perkin Elmer LS55 spectrophotometer.

${ }^{1} \mathrm{H}$ NMR spectra for all derivatives were measured in d6DMSO solvent, ${ }^{13} \mathrm{C}$ NMR spectrum was measured for only PA1. ${ }^{13} \mathrm{C}$ NMR for PA2 and PA3 couldn't obtained in different solvents even if measurement is carried out overnight.

\subsection{Synthesis and Characterization of PA Derivatives}

2.1.1 Synthesis of N,N-dimethyl-4-\{[4-(1Hphenanthro[9,10-d]imidazole-2-yl)pheyl]diazenyl $\}$ aniline (PA1)

An aqueous solution of $\mathrm{NaNO}_{2}(0.246 \mathrm{~g}, 3.56 \mathrm{mmol})$ were added dropwise to the cooled mixture of $1: 10 \mathrm{HCl}-$ water $(11 \mathrm{ml})$ and 4-(1H-phenanthro[9,10- $d]$ imidazole2-yl)aniline ( $1 \mathrm{~g}, 3.24 \mathrm{mmol})$. The mixture was stirred between $0-5{ }^{0} \mathrm{C}$ for $30 \mathrm{~min}$. N,N-dimethyl aniline $(0.4 \mathrm{ml}$, $3.24 \mathrm{mmol})$ and sodium acetate $(0.089 \mathrm{~g}, 1.08 \mathrm{mmol})$ were added separately to the diazonium salt which composed. The mixture was stirred for 1 more hour at 0 ${ }^{0} \mathrm{C}$ and neutralized with $2 \mathrm{~N} \mathrm{NaOH}$ solution. It was extracted with ethyl acetate and the organic fraction was dried over anhydrous $\mathrm{MgSO}_{4}$. The solvent was evaporated with a rotary evaporator. Recrystallization was performed from ethyl acetate. FT-IR [KBr, $v$ max $\left(\mathrm{cm}^{-1}\right)$ ]: 3072 (aromatic C-H stretch), 2902 (aliphatic C$\mathrm{H}$ stretch), 1600 ( $\mathrm{N}=\mathrm{N}$ stretch), 1518 (ring vib.), 1362 (C$\mathrm{N}$ stretch). ${ }^{1} \mathrm{H}-\mathrm{NMR}$ (d6-DMSO, $\left.400 \mathrm{MHz}\right) \quad \delta$ (ppm): $3.05\left(\mathrm{~s}, 6 \mathrm{H}, 2 \times \mathrm{CH}_{3}-\mathrm{N}\right)$, 6.82-6.84 (m, 2H, aromatic), 7.62-7.64 (m, 2H, aromatic), $7.74(\mathrm{t}, 2 \mathrm{H}$, aromatic, $\mathrm{j}=$ $8 \mathrm{~Hz}), 7.82-7.84(\mathrm{~m}, 2 \mathrm{H}$, aromatic), 7.97-7.99 (m, $2 \mathrm{H}$, aromatic), 8.44-8.47 (m, $2 \mathrm{H}$, aromatic), $8.59(\mathrm{~d}, 2 \mathrm{H}$, aromatic $\mathrm{j}=8 \mathrm{~Hz}), \quad 8.85(\mathrm{~d}, 2 \mathrm{H}$, aromatic $\mathrm{j}=8 \mathrm{~Hz}) .{ }^{13} \mathrm{C}$ NMR (d6-DMSO, $400 \mathrm{MHz}) \delta$ (ppm): 40.28 (2C), 112.06 (4C), 122.45 (1C), 122.91 (4C), 125.36 (4C), 127.38 (4C), 127.62 (2C), 131.40 (2C), 144.22 (2C), 148.95 (2C), 153 (2C). LC-MS (ESI) m/z=441.9 [M+].

\subsubsection{Synthesis of 4-\{[4-(1H-phenanthro[9,10- d]imidazol-2-yl)phenyl]diazenyl\}phenol (PA2)}

An aqueous solution of $\mathrm{NaNO}_{2}(0.06 \mathrm{~g}, 0.89 \mathrm{mmol})$ were added dropwise to the cooled mixture of 1:10 HCl-water $(11 \mathrm{ml})$ and 4-(1H-phenanthro[9,10- $d]$ imidazole-2yl)aniline $(0.25 \mathrm{~g}, 0.81 \mathrm{mmol})$. The mixture was stirred between $0-5{ }^{\circ} \mathrm{C}$ for $30 \mathrm{~min}$. Phenol $(0.076 \mathrm{~g}, 0.81 \mathrm{mmol})$ in $5 \mathrm{ml} 10 \% \mathrm{NaOH}$ were cooled to $0{ }^{\circ} \mathrm{C}$ and then added slowly to the diazonium salt which composed. The mixture was stirred for 1 more hour at $0{ }^{\circ} \mathrm{C}$ and it was brought to $\mathrm{pH} 8$ with $2 \mathrm{~N} \mathrm{NaOH}$ solution. It was extracted with ethyl acetate and the organic fraction was dried over anhydrous $\mathrm{MgSO}_{4}$. The solvent was evaporated. Recrystallization was performed from acetone. FT-IR [KBr, v $\left.\max \left(\mathrm{cm}^{-1}\right)\right]: 3421$ (O-H stretch), $3229(\mathrm{~N}-\mathrm{H}$ stretch), 3056 (aromatic C-H stretch), 1595 (N=N stretch), 1248 (C-O stretch). ${ }^{1} \mathrm{H}-\mathrm{NMR}$ (d6-DMSO, 400 $\mathrm{MHz}) \delta(\mathrm{ppm}): 6.96(\mathrm{~d}, 2 \mathrm{H}$, aromatic, $\mathrm{j}=8 \mathrm{~Hz}), 7.60-$ $7.64(\mathrm{~m}, 2 \mathrm{H}$, aromatic), 7.71-7.73 (m, 2H, aromatic), $7.85(\mathrm{~d}, 2 \mathrm{H}$, aromatic, $\mathrm{j}=8 \mathrm{~Hz}), 8.02(\mathrm{~d}, 2 \mathrm{H}$, aromatic, $\mathrm{j}=8 \mathrm{~Hz}), 8.48(\mathrm{~d}, 2 \mathrm{H}$, aromatic, $\mathrm{j}=8 \mathrm{~Hz}), 8.58(\mathrm{~d}, 2 \mathrm{H}$, aromatic, $\mathrm{j}=8 \mathrm{~Hz}), 8.83(\mathrm{~d}, 2 \mathrm{H}$, aromatic, $\mathrm{j}=8 \mathrm{~Hz}), 10.37$

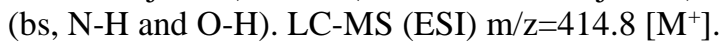


2.1.3 Synthesis of 1-\{[4-(1H-phenanthro[9,10d]imidazol-2-yl)phenyl]diazenyl\}-2-naphthol (PA3)

PA3 was prepared by the same procedure for PA2 using the 2-naphtol instead of phenol. FT-IR [KBr, $v$ max $\left(\mathrm{cm}^{-1}\right)$ ]: 3050 (aromatic $\mathrm{C}-\mathrm{H}$ stretch), $1614 \quad(\mathrm{~N}=\mathrm{N}$ stretch), 1494 (ring vib.), 1209 (C-O stretch). ${ }^{1} \mathrm{H}-\mathrm{NMR}$ (d6-DMSO, $400 \mathrm{MHz}) \delta(\mathrm{ppm}): 6.88(\mathrm{~d}, 1 \mathrm{H}$, aromatic, $\mathrm{j}=8 \mathrm{~Hz}), 7.43-7.47(\mathrm{~m}, 1 \mathrm{H}$, aromatic $), 7.60-7.64(\mathrm{~m}, 3 \mathrm{H}$, aromatic), 7.71-7.75 (m, 3H, aromatic), $7.92(\mathrm{~d}, 1 \mathrm{H}$, aromatic, $\mathrm{j}=8 \mathrm{~Hz}), 8.02(\mathrm{~d}, 2 \mathrm{H}$, aromatic, $\mathrm{j}=12 \mathrm{~Hz}), 8.44$ (d, $2 \mathrm{H}$, aromatic, $\mathrm{j}=12 \mathrm{~Hz}), 8.55-8.59(\mathrm{~m}, 3 \mathrm{H}$, aromatic), $8.82(\mathrm{~d}, 2 \mathrm{H}$, aromatic, $\mathrm{j}=8 \mathrm{~Hz})$. LC-MS (ESI) $\mathrm{m} / \mathrm{z}=464.8$ $\left[\mathrm{M}^{+}\right]$.

\section{Results and Discussion}

The photophysical properties of the PA derivatives were characterized in dimethylformamide (DMF), dichloromethane (DCM), chloroform $\left(\mathrm{CHCl}_{3}\right)$, tetrahydrofuran (THF) solvents by means of UV-vis absorption and emission spectroscopy. The spectroscopic studies of PA2 were made in DMF and THF solvents because it is only soluble in them.

Maximum absorption, emission and excitation wavelengths $\left(\lambda_{\max } ; \lambda_{\text {max }}^{\mathrm{f}} ; \lambda_{\mathrm{ex}}\right.$ in $\left.\mathrm{nm}\right)$, molar extinction coefficients $\left(\varepsilon\right.$; in $\left.\mathrm{L} \mathrm{mol}^{-1} \mathrm{~cm}^{-1}\right)$, singlet energy levels (Es, kj/mol), Stokes' shifts of PA derivatives for all solvents used are shown in Tables 1, 2, 3 .

Stokes' shift is the wavelength difference between the band maxima of the excitation and emission spectra of the same electronic transition.

Es calculations were estimated by $E=h \cdot \frac{c}{\lambda}$ formula.

(h: Planck constant, c: speed of light, $\lambda$ : maximum absorption wavelength)

\subsection{Absorption and Emission Studies of PA Derivatives in Different Solvents}

Spectroscopic studies for PA derivatives were carried out in the concentration of $1.0 \times 10^{-5} \mathrm{M}$. These derivatives exhibited maximum absorption wavelengths between 407-555 $\mathrm{nm}$ in all solvents used. The bands observed at UV-vis spectra below $400 \mathrm{~nm}$ can be attributed to the $\pi$ $\pi^{*}$ transitions. These bands can be seen in Figure 2 for all derivatives in THF. The peaks above $400 \mathrm{~nm}$ are related to the low energy $n-\pi^{*}$ transition.

For all derivatives, the emission band was obtained when excited nearly $\lambda_{\max 1}$. When PA derivatives were excited

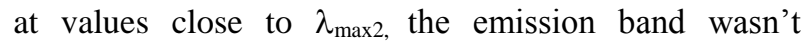
observed.

$\mathrm{n} \rightarrow \pi^{*}$ transition undergoes bathochromic shift with increasing polarity of solvent (Table 1,2 and 3) [19]. DMF has the highest polarity index in the solvents used.
All absorption spectra of PA derivatives were analyzed, bathochromic shift was observed for $\mathrm{n} \rightarrow \pi^{*}$ transition in DMF between 38-49 $\mathrm{nm}$ compared to the other solvents.

When $\lambda_{\max 2}$ values of PA derivatives are examined, it is seen that PA3 has the longest absorption wavelengths. This situation is probably due to the increasing electron donating effect of donor groups attached to the aromatic rings (Figure 2).

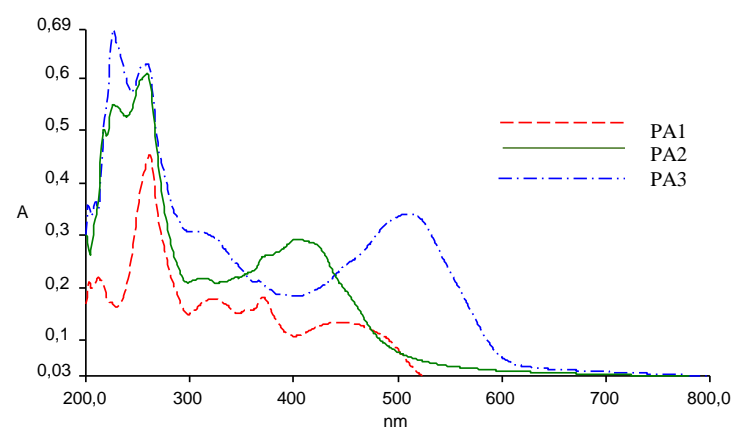

Figure 2. Absorption spectrum of PA derivatives in THF

The molar extinction coefficients of all PA derivatives were found to be enough for sensitizer cell applications [20]. It has varied between $8000-53000 \mathrm{Lmol}^{-1} \mathrm{~cm}^{-1}$ for $\varepsilon_{1}$ and $12000-37000 \mathrm{Lmol}^{-1} \mathrm{~cm}^{-1}$ for $\varepsilon_{2}$ in this study. The emission wavelengths were observed between 380-428 $\mathrm{nm}$ for all derivatives. Figure 3 shows the emission and excitation spectrum of PA3 in all solvents used. This derivative showed a bathochromic shift approximately between 8-28 $\mathrm{nm}$ compared to the other derivatives (Table 1, 2 and 3). This situation can be explained by the enhancement of electron-charge transfer due to longer conjugation.

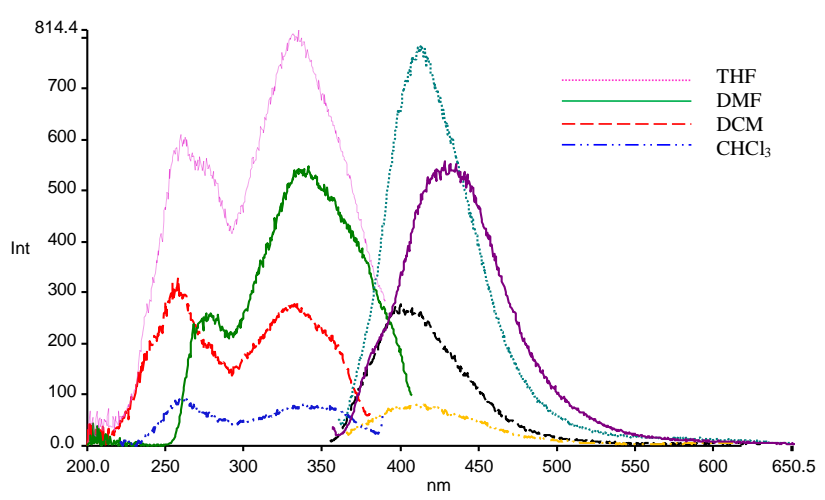

Figure 3. Emission and excitation spectrum of PA3 in all solvents used.

The singlet energy levels (Es) of all derivatives were estimated to be about 87.25-92.63 for $\mathrm{Es}_{1}$ and 51.41$70.09 \mathrm{kcal} / \mathrm{mol}$ for $\mathrm{Es}_{2}$ in solutions. A large Stokes' shift is often highly desirable for fluorescence measurements in sensor studies. In this study, Stokes' shift values were found in the range of 60-92 $\mathrm{nm}$ in solutions. These values are acceptable for many fluorescence applications. 
Table 1. UV-vis spectroscopic data $\left(\lambda / \mathrm{nm}, \varepsilon / \mathrm{Lmol}^{-1} \mathrm{~cm}^{-1}\right)$ and emission spectroscopic data (Es, $\left.\mathrm{kcal} / \mathrm{mol}\right)$ of PA1 in different solvents.

\begin{tabular}{|c|c|c|c|c|c|c|c|c|c|c|}
\hline Solvent & C (M) & $\begin{array}{l}\lambda_{\max 1} \\
(\mathbf{n m})\end{array}$ & $\begin{array}{l}\lambda_{\max 2} \\
(\mathrm{~nm})\end{array}$ & $\begin{array}{l}\lambda_{\text {ex. }} \\
(\mathbf{n m})\end{array}$ & $\begin{array}{l}\lambda_{\text {max }}^{\mathrm{f}} \\
(\mathbf{n m})\end{array}$ & $\begin{array}{c}\varepsilon_{1} \\
\mathrm{Lmol}^{-1} \mathbf{c m}^{-1}\end{array}$ & $\begin{array}{c}\varepsilon_{2} \\
\mathrm{Lmol}^{-1} \mathbf{c m}^{-1}\end{array}$ & $\Delta \lambda$ & $\begin{array}{c}\text { Es1 }_{\text {s1 }} \\
\text { kcal/ } \\
\text { mol }\end{array}$ & $\begin{array}{c}\text { ES2 }_{\text {S2 }} \\
\text { kcal/ } \\
\text { mol }\end{array}$ \\
\hline DCM & \multirow{4}{*}{$1.0 \times 10^{-5}$} & 321 & 455 & 320 & 380 & 11000 & 20000 & 60 & 88.88 & 62.70 \\
\hline DMF & & 315 & 500 & 323 & 400 & 53000 & 18000 & 77 & 90.57 & 57.06 \\
\hline $\mathrm{CHCl}_{3}$ & & 319 & 451 & 325 & 389 & 8000 & 15000 & 64 & 89.44 & 63.30 \\
\hline THF & & 319 & 451 & 325 & 394 & 18000 & 13000 & 69 & 89.44 & 63.30 \\
\hline
\end{tabular}

Table 2. UV-vis spectroscopic data $\left(\lambda / \mathrm{nm}, \varepsilon / \mathrm{Lmol}^{-1} \mathrm{~cm}^{-1}\right)$ and emission spectroscopic data (Es, $\left.\mathrm{kcal} / \mathrm{mol}\right)$ of PA2 in different solvents.

\begin{tabular}{|c|c|c|c|c|c|c|c|c|c|c|}
\hline Solvent & $\mathrm{C}(\mathrm{M})$ & $\begin{array}{l}\lambda_{\max 1} \\
(\mathbf{n m})\end{array}$ & $\begin{array}{l}\lambda_{\max 2} \\
(\mathrm{~nm})\end{array}$ & $\begin{array}{c}\lambda_{\text {ex. }} \\
(\mathbf{n m})\end{array}$ & $\begin{array}{l}\lambda_{\max }^{\mathrm{f}} \\
(\mathbf{n m})\end{array}$ & $\begin{array}{c}\varepsilon_{1} \\
\mathrm{Lmol}^{-1} \mathbf{c m}^{-1}\end{array}$ & $\begin{array}{c}\varepsilon_{2} \\
\mathrm{Lmol}^{-1} \mathbf{c m}^{-1}\end{array}$ & $\Delta \lambda$ & $\begin{array}{c}\text { Es1 }_{S 1 /} \\
\text { kcal/ } \\
\text { mol }\end{array}$ & $\begin{array}{c}\mathrm{E}_{\mathrm{S2}} \\
\mathrm{kcal} / \\
\mathrm{mol}\end{array}$ \\
\hline DMF & \multirow{2}{*}{$1.0 \times 10^{-5}$} & 308 & 456 & 325 & 401 & 39000 & 37000 & 76 & 92.63 & 62.57 \\
\hline THF & & 309 & 407 & 328 & 404 & 17000 & 24000 & 76 & 92.33 & 70.09 \\
\hline
\end{tabular}

Table 3. UV-vis spectroscopic data $\left(\lambda / \mathrm{nm}, \varepsilon / \mathrm{Lmol}^{-1} \mathrm{~cm}^{-1}\right)$ and emission spectroscopic data (Es, $\left.\mathrm{kcal} / \mathrm{mol}\right)$ of PA3 in different solvents.

\begin{tabular}{|c|c|c|c|c|c|c|c|c|c|c|}
\hline Solvent & $\mathrm{C}(\mathrm{M})$ & $\begin{array}{r}\lambda_{\max 1} \\
(\mathbf{n m})\end{array}$ & $\begin{array}{l}\lambda_{\max 2} \\
(\mathrm{~nm})\end{array}$ & $\begin{array}{l}\lambda_{\text {ex. }} \\
(\mathbf{n m})\end{array}$ & $\begin{array}{l}\lambda^{\mathrm{f}}{ }_{\max } \\
(\mathbf{n m})\end{array}$ & $\begin{array}{c}\varepsilon_{1} \\
\mathrm{Lmol}^{-1} \mathrm{~cm}^{-1}\end{array}$ & $\begin{array}{c}\varepsilon_{2} \\
\mathrm{Lmol}^{-1} \mathrm{~cm}^{-1}\end{array}$ & $\Delta \lambda$ & $\begin{array}{c}\text { E}_{\text {S1 }} \\
\text { kcal/ } \\
\text { mol }\end{array}$ & $\begin{array}{c}\text { Es2 } \\
\text { kcal/ } \\
\text { mol }\end{array}$ \\
\hline DCM & \multirow{4}{*}{$1.0 \times 10^{-5}$} & 327 & 516 & 331 & 403 & 9000 & 12000 & 72 & 87.25 & 55.30 \\
\hline DMF & & 309 & 555 & 336 & 428 & 50000 & 34000 & 92 & 92.33 & 51.41 \\
\hline $\mathrm{CHCl}_{3}$ & & 320 & 517 & 341 & 408 & 12000 & 21000 & 67 & 89.16 & 55.18 \\
\hline THF & & 309 & 510 & 332 & 412 & 31000 & 34000 & 80 & 92.33 & 55.94 \\
\hline
\end{tabular}

\subsection{Photostability Studies}

Photostability studies of PA derivatives were performed by using a steady state spectrofluorimeter in the mode of "Time Based Measurements" employing a xenon arc lamp. All of the fluorophores were excited at around 370 $\mathrm{nm}$, the data were obtained at their maximum emission wavelengths for one hour monitoring.

The steady results were obtained for all derivatives. The photostability results of PA3 in solvent media can be seen in Figure 4.

\section{Conclusions}

New compounds containing phenanthroimidazole ring were added to the azo dye classes by means of this study. These derivatives can be used in many different application fields with their fluorescence properties. Spectroscopic characterizations for synthesized PA derivatives were performed in different solvents. When the maximum absorption wavelengths were examined in studied solvents, the bathochromic shift was observed in DMF for all derivatives for $n-\pi^{*}$ transition. Depending on the increased conjugation, PA3 exhibits a bathochromic shift in emission spectra relative to other derivatives.

The photostability tests were performed in solvent media. Results showed that all derivatives were photostable for one hour in different solvents.

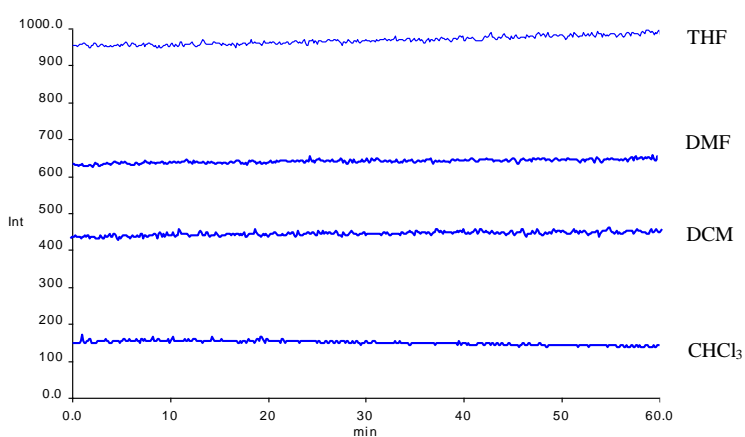

Figure 4. Photostability results of PA3 in all studied solvents. 


\section{Acknowledgements}

This work was financially supported by Manisa Celal Bayar University Research Fund (MCBU BAP: 2013096)

\section{References}

1. Fleischmann, $C$, Lievenbrück, $M$, Ritter, H, Polymers and Dyes: Developments and Applications, Polymers, 2015, 7, 717-746.

2. Rizk, H.F, Ibrahim, S.A, El-Borai, M.A, Synthesis, fastness properties, color assessment and antimicrobial activity of some azo reactive dyes having pyrazole moiety, Dyes and Pigments, 2015, $112,86-92$.

3. Guru Prasad, L, Azo Dye Doped Polymer Films for Nonlinear Optical Applications, Chinese Journal of Polymer Science, 2014, $32,650-657$.

4. Ahmad, B, Bhatti, I.A, Saeed, Q, Abbas, M, Synthesis and Applications of Three Vinylsulfone Based Fiber-Reactive Azo Dyes for Dyeing Cotton Fabric, International Journal of Basic\&Applied Sciences, 2012, 12, 129-136.

5. Miladinova, P.M, Vaseva, R.K, Lukanova, V.R, Synthesis and Investigation of Some Acid Azo Dyes for Wool, Journal of Chemical Technology and Metallurgy, 2015, 50, 20-25.

6. Krishna, N.V, Krishna Jonnadula, V.S, Singh, S.P, Giribabu, L, Islam, A, Bedja, I.M, Bulky Nature Phenanthroimidazole Based Porphyrin Sensitizers for Dye-Sensitized Solar Cell Applications, The Journal of Physical Chemistry C, 2017, 121, 25691-25704.

7. Huang, H, Wang, Y, Zhuang, S, Yang, X, Wang, L, Yang, C, Simple Phenanthroimidazole/Carbazole Hybrid Bipolar Host Materials for Highly Efficient Green and Yellow Phosphorescent Organic Light-Emitting Diodes, The Journal of Physical Chemistry C, 2012, 116, 19458-19466.

8. Butkute, R, Lygaitis, R, Mimaite, V, Gudeika, D, Volyniuk, D, Sini, G, Grazulevicius, J.V, Bipolar highly solid-state luminescent phenanthroimidazole derivatives as materials for blue and white organic light emitting diodes exploiting either monomer, exciplex or electroplex emission, Dyes and Pigments, 2017, 146, 425-437.

9. Wang, Z, Lu, P, Chen, S, Gao, Z, Shen, F, Zhang, W, Xu, Y, Kwok, H.S and Ma, Y, Phenanthro[9,10-d]imidazole as a new building block for blue light emitting materials, Journal of Materials Chemistry, 2011,21, 5451-5456.

10. Ferreira, R.C.M, Costa, S.P.G, Gonçalves, H, Belsley, $M$ and Raposo, M.M.M, Fluorescent phenanthroimidazoles functionalized with heterocyclic spacers: synthesis, optical chemosensory ability and two-photon absorption (TPA) properties, New Journal of Chemistry, 2017, 41, 12866-12878.

11. Barton, J.W, Grinham, A.R, Phenanthro[9,10-d]imidazole Derivatives. The Structure of Zincke's Phenanthraquinone lmide Anhydride, Journal of the Chemical Society (C), 1971, 0, 12561259 .

12. Itano, H.A, Yamada, S, 2-Aminophenanthroimidazole, fluorescent product of the reaction of phenanthrenequinone with arginine, Analytical Biochemistry, 1972, 48(2), 483-490.

13. Srinivasan, P.R, Srinivasan, M, Mahadevan, V, Preparation and properties of polybenzimidazoles containing azo groups, Journal of Polymer Science, 1982, 20(4), 1145-1150.

14. Gianfranco, S, Guido, A, Affinity and dyeing rate on secondary cellulose acetate fiber of some heterocyclic disperse azo dyes, Annali di Chimica, 1984, 74, 623-625.
15. Steck, E.A, Day, A.R, Reactions of Phenantroquinone and retenequinone with aldehydes and ammonium acetate in acetic acis solution, Journal of American Chemical Society, 1943, 65, 452456.

16. Satapathy, R, Wu, Y.H, Lin, H.C, Novel dithieno-benzoimidazole-based $\mathrm{Pb}^{2+}$ sensors: substituent effects on sensitivity and reversibility, Chemical Communications, 2012, 48, 5668-5670.

17. Carella, A, Centore, R, Fort, A, Peluso, A, Sirigu, A, Tuzi, A, Tuning Second-Order Optical Nonlinearities in Push-Pull Benzimidazoles, European Journal of Organic Chemistry, 2004 $12,2620-2626$.

18. Alredha, R, Al-Rubaie, L, Mhessn, R.J, Synthesis and characterization of azo dye para red and new derivatives. E-Journal of Chemistry, 2012, 9, 465-470.

19. Masoud, M.S, Ali, A.E, Shaker, M.A, Ghani, M.A, Solvatochromic behavior of the electronic absorption spectra of some azo derivatives of amino pyridines, Spectrochimica Acta Part A, 2004, 60, 3155-3159.

20. Lee, C, Yum, J.H, Choi, H, Kang, S.O, Ko, J, Humphry-Baker R, Gratzel, M, Nazeeruddin, K, Phenomenally High Molar Extinction Coefficient Sensitizer with "Donor-Acceptor" Ligands for DyeSensitized Solar Cell Applications, Inorganic Chemistry, 2008, 47 , 2267-2273. 